\title{
A STUDY ON INCURABLE BLINDNESS IN A RURAL COMMUNITY OF WEST MIDNAPUR DISTRICT, WEST BENGAL, INDIA
}

\author{
Krishna Pada Baidya1, Smaranjit Biswas², Pramit Ghosh ${ }^{3}$
}

${ }^{1}$ Associate Professor, Department of Ophthalmology, Regional Institute of Ophthalmology Medical College, Kolkata. 2Residential Medical Officer Cum Clinical Tutor, Regional Institute of Ophthalmology Medical College, Kolkata. ${ }^{3}$ Assistant Professor, Department of Community Medicine, Medical College, Kolkata.

ABSTRACT
BACKGROUND
Blindness has long been recognised as a public health concern in India. The study aimed to assess the burden of incurable blindness
and explore the available and accessible rehabilitation measures in rural community.

\section{MATERIALS AND METHODS}

A cross-sectional study was undertaken among two blocks of West Midnapur district, West Bengal using a pre-designed, pre-tested semi-structured proforma by trained ophthalmologist from a Medical College Hospital.

\section{RESULTS}

The study identified 212 eyes of 106 incurably blind individuals. Age range was 5-75 yrs. with median age of 22 yrs. Median duration was 18 years; 68 individuals were blind since birth (64.15\%); 131 eyes (54.71\%) had causes dating back to their birth or early childhood. Coloboma with microphthalmos were the leading cause accounting for 36 cases (16.98\%). Congenital cataract 22 (10.37\%), microphthalmos with microcornea 17 (8.01\%) and nystagmus without ocular pathology 14 (6.60\%) were other leading causes. Diseases acquired later childhood or adulthood accounted for 81 out of the 212 eyes (38.20\%). Retinitis pigmentosa 18 (8.49\%), bilateral keratitis 14 (6.60\%), adult glaucoma 08 (3.77\%) and high myopia with chorioretinal degeneration 08 (3.77\%) were also found; 3 persons were admitted to blind school, 6 were receiving financial support but none aware of any Community Based Rehabilitation (CBR); 71 eyes (33.49\%) out of 212 were lost from preventable causes of which 36/131 were (27.48\%) in children and 35/81 (43.20\%) in adult age groups.

\section{CONCLUSION}

The study highlights need for early screening and comprehensive rehabilitation approach to reduce the burden of incurable blindness in the community.

\section{KEYWORDS}

Blindness, Rehabilitation, Community.

HOW TO CITE THIS ARTICLE: Baidya KP, Biswas S, Ghosh P. A study on incurable blindness in a rural community of West Midnapur district, West Bengal, India. J. Evolution Med. Dent. Sci. 2016;5(85):6339-6344, DOI: 10.14260/Jemds/2016/1432

\begin{tabular}{l} 
BACKGROUND \\
Blindness is a major public health concern in India, which \\
creates a huge economic burden to our economy. Blindness \\
can be classified and graded according to severity, \\
pathogenesis, treatability or its implication in our daily life. In \\
spite of our best of efforts and intent, a proportion of persons \\
with visual disability remains incurably blind and need life- \\
long support and aids to lead a functional life. Rehabilitation \\
with all four domains namely medical, vocational, social and \\
psychological needs to be available and accessible to them for \\
achieving full potential. Specifically, visual rehabilitation can \\
be defined as a process of treatment and education that helps \\
visually disabled individuals attain maximum function, a sense \\
of wellbeing, independence and optimum quality of life. \\
Function is maximised by evaluation, diagnosis and treatment \\
\hline Financial or Other, Competing Interest: None. \\
Submission 23-08-2016, Peer Review 10-10-2016, \\
Acceptance 17-10-2016, Published 24-10-2016. \\
Corresponding Author: \\
Dr. Smaranjit Biswas, \\
C/o. M. K. Biswas, Milanpalli, \\
P. O. Hridaypur, Dist. 24 Parganas (North), \\
Kolkata-700127, West Bengal. \\
E-mail: smaranjitbiswas@gmail.com \\
DOI: 10.14260 /jemds/2016/1432 \\
@C) By No
\end{tabular}
including but not limited to the prescription of optical, nonoptical, electronic and/or other assistive treatment options. The rehabilitation process includes the development of an individual plan of care specifying clinical therapy and/or training in compensatory approaches. ${ }^{[1]}$

However, the issues related to incurable blindness are not easily addressed at community level. Diagnosing the person as incurably blind and formal certification is a complex process. It includes multiple visits to tertiary care centre, extensive travel time and wage loss for accompanying persons. Simultaneously stigma and psychological trauma, social ostracism have to be deal with. Awareness on importance of a proper diagnosis, a valid certification along with scopes of rehabilitation measures has not been satisfactory enough to act as a pull factor to gauge the extent of the problem at community level. With this background, the present study was undertaken with the following objectives.

The Present Study of Blindness was undertaken in a Rural Community of India in Order to

1. To estimate the burden of incurable blindness in the district of Paschim Midnapur, West Bengal.

2. To find out the aetiologies of incurable blindness in the district. 
3. To explore the awareness, availability and accessibility of facilities to address problems of blindness and low vision.

\section{MATERIALS AND METHODS}

The study was conducted in the district of West Midnapur, located in the South Western of West Bengal, India. The study was undertaken jointly by district health department and Department of Ophthalmology of the Medical College Hospital, located in West Midnapur district of West Bengal. It was a population based cross-sectional study on visual impairment. The study was conducted in the year 2010-2012. The district has a population of 5913457 as per 2011 census resides in 9780 sq. $\mathrm{km}$ area, of which $87.9 \%$ reside in rural area. It is divided into 29 administrative units called community development blocks. The blocks are further divided into gram panchayats (total 290), which are formed by elected representatives of villages in that area. There are more than 7500 villages in the district. Health care is provided by frontline workers at village level. For each of 5 or 6 villages, one sub health centre is there to cater to the basic health needs of the population. At block level one block hospital is there manned by doctors and other indoor staff. The study was carried out in 2 such blocks namely Daspur-I comprising of 10 Gram Panchayats and 157 villages and Chandrakona with 126 villages distributed over 6 gram panchayats. The total population of the blocks was 339993. At the outset in consultation with district blindness control society, a plan was drawn up to undertake the research. The institutional approval was obtained. All concerned health workers and para-medical ophthalmic assistants were sensitised about the study and were oriented on the specific roles and responsibilities of each and every individual. The Health Workers (HW) and ASHA (Accredited Social Health Activist) carried out IPC for mobilising the community for eye health camps. The camps were organised at village level in subcentres (wherever available) or in primary schools or Anganwadi centres (Established for nutritional intervention). A total of 281 camps were organised for the population residing in 286 habitations. The camps were manned by PMOA and HWs supervised by Public Health Nurses/Block Public Health Nurses/Lady Health Volunteers/Health Supervisors. They screened all the persons attending the camp for reduced visual acuity by use of Snellen's chart. In each village, multiple camps were required. The camps were also used for eye health communication through group discussion with a focus on cataract, eye problems related to ever increasing noncommunicable diseases and healthy dietary practices.

All those identified with reduced visual acuity were enlisted and were referred to a comprehensive eye examination camp held at GP head quarter level within next one month. The individuals were mobilised by ASHA and HW for these camps at GP head quarter. All individuals with reduced vision were brought to eye camps by trained field workers and ophthalmic assistants where they were examined by qualified ophthalmologists. For some specific investigations, the selected persons were brought to the Medical College, Ophthalmology Department on a pre-fixed date. Those who were found to have curable diseases were given appropriate management. Cases were diagnosed after obtaining a detailed history, examination and necessary investigations like slit-lamp biomicroscopy, indirect ophthalmoscopy, applanation tonometry, USG-B scan, fundus fluorescein angiography, ERG, EOG and VEP. A selfadministered questionnaire based proforma was filled up for each patient. The questionnaire was developed with a focus on exploring awareness of the subjects on availability and accessibility of facilities and resources in the local community for addressing problem of blindness, schools for the blinds, aids for low vision, etc. Individuals were considered blind and issued certificate if they had distant visual acuity of less than $6 / 60$ in their better eye with best possible correction (NPCB criteria). The activities were carried out Gram Panchayat wise. Number of camps required for initial screening were 3 to 4 in each village. Similarly, in the later phase also, 40 camps by trained ophthalmologist with all necessary instruments were held. In each gram panchayat, about 3-6 camps with ophthalmologists were necessary to examine all the screened subjects.

\section{RESULTS}

From the village level camps, 156812 persons came for checkup and $3578(2.28 \%)$ persons were identified with reduced visual acuity (VA $<6 / 60$ with BCVA); 451 persons out of them did not attend the next level check-up camps held at GP headquarters due to personal problems or in case of few health workers failed to contact them before the next camp. Out of all those 3127 persons examined, 212 eyes of 106 (3.39\%) incurably blind patients were identified in the study. The subjects were aged between 5 to 75 years, $27.35 \%$ being in the 5-18 years old age group.

Out of 106 blind persons, 52 (49.05\%) were male and 54 $(50.95 \%)$ were female. The median age for incurably blind persons was 22 years. The median duration of blindness was 18 years as revealed from history; 68 individuals blind since birth were (64.15\%). Majority of them were from poor socioeconomic background.

There were 44 cases registered with loss of vision in one eye; 23 (52.27\%) were male and 21 (47.73\%) were female. Among the 44 cases, corneal opacity following keratitis accounted for 18 (40.90\%) followed by trauma $12(27.27 \%)$, congenital anomaly 09 (20.45\%), amblyopia 03 (6.81\%), others $04(9.09 \%)$ and related to poor cataract surgery 03 (6.81\%).

So far as aetiology of blindness was concerned, 131 eyes (54.71\%) out of the 212 eyes were affected since birth or early childhood. Fundal and Iris coloboma with Microphthalmos, Congenital cataract, Retinitis pigmentosa, Microphthalmos with micro-cornea, Nystagmus without ocular pathology, bilateral keratitis either with defective PR or absence of PL accounted for $57 \%$ of aetiologies. Other than these aforementioned 6 ophthalmologists diagnosed 29 more aetiologies leading to incurable pathology in the eyes of the subjects. The spectrum is wide, ranging from $3.77 \%$ cases of adult glaucoma, chorioretinal degeneration to a single case diagnosed as cryptophthalmos.

The causes acquired in late childhood or adulthood accounted for the remaining 81 out of the 212 eyes (38.20\%), retinitis pigmentosa accounted for 18 eyes (8.49\%), bilateral keratitis either with defective PR or absence of PL 14 (6.60\%), adult glaucoma 08 (3.77\%), high myopia with severe chorioretinal degeneration $08(3.77 \%)$, cataract surgery related complication 03 (1.41\%), AION+ optic neuritis 04 (1.88\%), macular dystrophy 04 (1.88\%), optic atrophy resulted from CNS tumour 03 (1.41\%), ocular injury 04 
(1.88\%), retinal detachment $03(1.41 \%)$, advanced diabetic retinopathy $02(0.94 \%)$, ARMD 02 (0.94\%), corneal dystrophy 02 (0.94\%), higher centre problem $02(0.94 \%)$, posterior uveitis 02 (0.94\%), Eales' disease 02 (0.94\%) [Refer Table No. $1]$.

Out of the total of 106 patients, only 16 (15.09\%) patients were aware of the existence of blind schools. When asked about blind schools, a few of them responded like "are you joking doctor? Can a blind person read?" Only 3 (2.83\%) got admitted in blind school with the help of local NGO. A meagre $5.6 \%$ (6 patients) were receiving some kind of financial help for being visually handicapped from Government Organisations. No one had received any Community Based Rehabilitation (CBR) from NGO or the Government. None of them were using low-vision aids. There was no blind school within $50 \mathrm{kms}$. from their locality.

\begin{tabular}{|c|c|c|c|c|}
\hline \multicolumn{5}{|c|}{ Aetiology of Blindness in Affected Eyes $(n=212)$} \\
\hline Sl. No. & Aetiology & No. & $\%$ & Cumulative Percentage \\
\hline 1 & Fundal and iris coloboma + microphthalmos & 36 & $16.98 \%$ & $16.98 \%$ \\
\hline 2 & Congenital cataract & 22 & $10.38 \%$ & $27.36 \%$ \\
\hline 3 & Retinitis pigmentosa & 18 & $8.49 \%$ & $35.85 \%$ \\
\hline 4 & Microphthalmos with micro-cornea & 17 & $8.02 \%$ & $43.87 \%$ \\
\hline 5 & Nystagmus without ocular pathology*** & 14 & $6.60 \%$ & $50.47 \%$ \\
\hline 6 & $\begin{array}{l}\text { Bilateral keratitis either with defective PR or absence of } \\
\text { PL }\end{array}$ & 14 & $6.60 \%$ & $57.08 \%$ \\
\hline 7 & Adult glaucoma & 8 & $3.77 \%$ & $60.85 \%$ \\
\hline 8 & High myopia with severe chorioretinal degeneration & 8 & $3.77 \%$ & $64.62 \%$ \\
\hline 9 & Albinism + nystagmus & 6 & $2.83 \%$ & $67.45 \%$ \\
\hline 10 & Congenital anophthalmos & 5 & $2.36 \%$ & $69.81 \%$ \\
\hline 11 & Infective corneal opacity with nystagmus & 4 & $1.89 \%$ & $71.70 \%$ \\
\hline 12 & Micro-ophthalmia + congenital cataract & 4 & $1.89 \%$ & $73.58 \%$ \\
\hline 13 & Congenital glaucoma & 4 & $1.89 \%$ & $75.47 \%$ \\
\hline 14 & AION + optic neuritis & 4 & $1.89 \%$ & $77.36 \%$ \\
\hline 15 & Macular dystrophy & 4 & $1.89 \%$ & $79.25 \%$ \\
\hline 16 & Ocular injury & 4 & $1.89 \%$ & $81.13 \%$ \\
\hline 17 & Cataract surgery related complications & 3 & $1.42 \%$ & $82.55 \%$ \\
\hline 18 & Optic atrophy resulting from CNS tumour & 3 & $1.42 \%$ & $83.96 \%$ \\
\hline 19 & Retinal detachment & 3 & $1.42 \%$ & $85.38 \%$ \\
\hline 20 & Sclera-cornea & 2 & $0.94 \%$ & $86.32 \%$ \\
\hline 21 & Nystagmus with optic atrophy & 2 & $0.94 \%$ & $87.26 \%$ \\
\hline 22 & Anterior staphyloma & 2 & $0.94 \%$ & $88.21 \%$ \\
\hline 23 & Optic atrophy & 2 & $0.94 \%$ & $89.15 \%$ \\
\hline 24 & Telecanthus + severe ptosis & 2 & $0.94 \%$ & $90.09 \%$ \\
\hline 25 & Hydrocephalus & 2 & $0.94 \%$ & $91.04 \%$ \\
\hline 26 & Microcephalus & 2 & $0.94 \%$ & $91.98 \%$ \\
\hline 27 & Retinopathy of prematurity & 2 & $0.94 \%$ & $92.92 \%$ \\
\hline 28 & Bilateral retinoblastoma & 2 & $0.94 \%$ & $93.87 \%$ \\
\hline 29 & Advanced diabetic retinopathy & 2 & $0.94 \%$ & $94.81 \%$ \\
\hline 30 & ARMD & 2 & $0.94 \%$ & $95.75 \%$ \\
\hline 31 & Corneal dystrophy & 2 & $0.94 \%$ & $96.70 \%$ \\
\hline 32 & Higher centre problem & 2 & $0.94 \%$ & $97.64 \%$ \\
\hline 33 & Posterior uveitis & 2 & $0.94 \%$ & $98.58 \%$ \\
\hline 34 & Eales' disease & 2 & $0.94 \%$ & $99.53 \%$ \\
\hline 35 & Cryptophthalmos & 1 & $0.47 \%$ & $100.00 \%$ \\
\hline & Total & 212 & $100 \%$ & \\
\hline
\end{tabular}




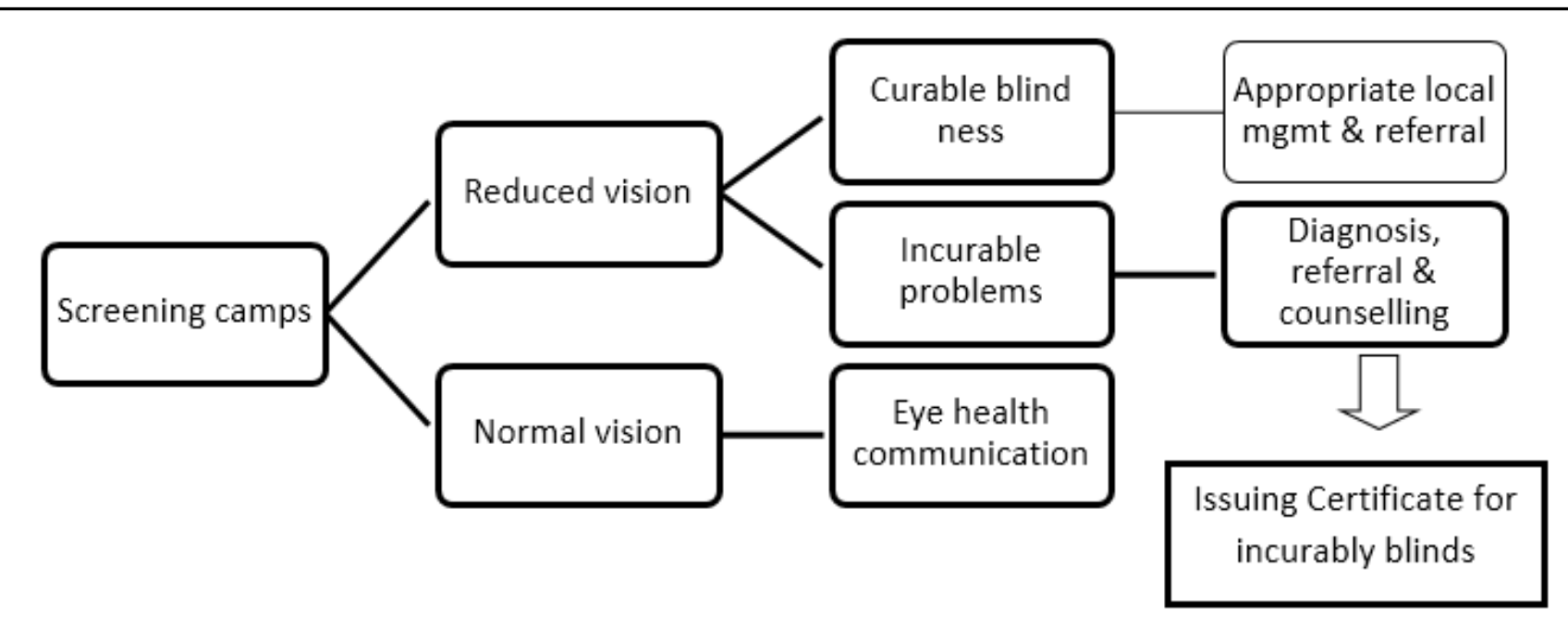

Figure 1. Study design

\section{DISCUSSION}

There are 39 million blind people worldwide and a quarter of the worldwide blind population lives in India.[2,3] The current population of India lies at 122 crores as per the 2011 census. ${ }^{[4]}$ Considering the current population, 75 lakhs ( 7.5 million) are due to cataract and 46.36 lakhs ( 4.6 million) are affected by other ocular pathology.[5] The survey conducted by Ministry of Health and Family Welfare (MOH and FW) during the year 2006-07 revealed that the prevalence of avoidable blindness has come down from $1.4 \%$ to $1 \% .{ }^{[6]}$ The prevalence of incurable blindness is not well documented in India. In our country poverty, illiteracy and lack of poor health infrastructure are the major factors responsible for the higher prevalence of blindness. Prevalence of preventable form of blindness has decreased in the recent years, thanks to extensive focus on cataract surgery and awareness on glaucoma and refractive error problems. But scarcity of trend analysis for incurable blindness undermines its public health importance. A majority of our country's rural population does not have access to specialised diagnostic and management facilities for the incurable blindness. Infective keratitis, trauma by vegetative matter, vitamin-A deficiency, chemical injury specially during Holi festival, burn and blast injury from fire crackers during Diwali festival, inappropriate home remedies and poor quality surgeries are important causes of preventable blindness.

Life with incurable blindness has traditionally been considered a major handicap in our everyday life. However, the visually challenged, differently-abled persons can excel with a little support from the society.

The study aimed to explore scope for better social life of blind people through rehabilitation process so that they can spend a useful and productive life whereby they can enjoy selfrespect and dignity in their family and society apart from decreasing the financial burden they pose to their family.

Around the world especially in the developed countries, there has been a considerable amount of attention towards rehabilitation of patients with low vision. There has been a rise of medicine model of vision rehabilitation in the recent years, spearheaded by and within ophthalmology.[7-9] In 2002, Medicare recognised this and responded by providing national coverage for the medicine model of low vision rehabilitation for those with central scotomas, acuities $<20 / 70$ or field loss considering its benefits akin to physical rehabilitation medicine for mobility impairments. State services for the blind are fiscally challenged in meeting these needs and only a few countries are sufficiently funded to meet the different vision rehabilitation needs of the escalating number of visually impaired adults over 65 .

In the study, congenital malformations $69(32.54 \%)$ was found as the leading cause of blindness followed by congenital cataract $22(10.37 \%)$. Among the acquired diseases most common causes were infective keratitis 18 (8.49\%), squint 14 (6.60\%) and retinal pigmentary changes 18 (8.49\%). As far as the causes for unilateral blindness were concerned, infective keratitis was the leading cause (18 out of 44 , i.e. $40.90 \%$ ) followed by trauma accounting for 12 cases $(27.27 \%)$. A total of 36 eyes out of 131 (27.48\%) in children and 35 out of 81 $(43.20 \%)$ in adult age groups were causes, which were amenable to timely intervention and thus preventable causes of blindness. If we look at the total figure, 71 eyes out of the total of 212 blind eyes (33.49\%) were actually preventable if timely intervention was done. This highlights that current activities of our national programs and NGO's are not enough to tackle the preventable causes of childhood blindness like congenital cataract, ROP, congenital glaucoma and infective keratitis, the solution of which can potentially bring down the amount of disability years lived by blind people by a huge extent.

Most interesting aspect which came out from our study was that only 03 out of the 106 patients (2.83\%) were admitted in blind school. Their schools were residential as there was no blind school within $50 \mathrm{kms}$. area of their home. An astonishing fact was that only 06 blind patients got economic help from the government. This figure indicates the agonising plight of the visually handicapped persons in our nation. None of them received Community Based Rehabilitation (CBR) like mobility training and vocational training. The mobility and orientation training is necessary for a blind individual to help him/her adapt to his/her surroundings in a manner that he/she can become independent in tasks like walking short distances without much help. Making these people capable enough for carrying out their daily life routine skills like washing, dressing, cooking 
and maintaining hygiene and other essential activities can bring out remarkable difference in their quality of life. Apart from that, vocational training for suitable and appropriate jobs can even make these people contribute to our growing economy along with being a morale booster and a source of income to them. The aim of economic rehabilitation can be like running small business ventures like animal rearing, specific agricultural works, crafts making e.g. toys, chair, basket, brooms, etc. Rehabilitation can even be initiated at home or within the community of these people, which can ensure all time active support to these people.

Another significant fact noted by us was that no special attention had been paid towards the blind children. There exists a serious lack of infrastructural facilities to combat preventable congenital causes of blindness like congenital cataract. This in turn adds to the amount of years lived with disability by these children and this accounts for adverse socioeconomic impact for a community. These children need integrated education with a holistic approach for their physical, mental and social wellbeing. Ideally, every blind child should get education preferably in normal school instead of blind school in their own villages along with other normal children. This can promote their all-round development and help them develop better understanding with their peers. Blind children should get training for mobility, activities for daily living, Braille education and low vision aids by a trained teachers. Parents of such children should also be trained, so that they can assist their children in this regard. We also noted that delay in initiation of treatment resulted in bilateral blindness in many otherwise treatable conditions like cataract, glaucoma and keratitis. Many of these patients had used home remedies instead of seeking advice from health professionals. The so called home remedies used in many rural households for eye diseases need to be seriously avoided as more often they do more of harm than good.

Visual Acuity (VA) at presentation less than 6/60 in the better eye has been referred to as economical blindness in India. [3] The annual economic burden of blindness in India based on the year 1997 estimated around \$4.4 billion. [10] In economic terms, the cost of blindness depends on the direct cost incurred by the blind person due to loss of productivity and indirect cost incurred by the family to take care of the blind person. The average number of working years lost due to adult blindness is 10 years and in case of blind children it is 33 years. ${ }^{[6]} 10 \%$ of the productive time of one economically productive member of the family of each blind person is lost in taking care of the blind. [9] One major problem in formulation of effective policies is that there is no nation-wide data from well-designed population based studies on blindness. There are only few data available in this regard on regional basis. The national survey done during 1986-89 did not include dilated fundus examination and visual field assessment. Hence, retinal diseases and others non-cataractous causes of blindness were underestimated. The Andhra Pradesh Eye Disease Study (APEDS) was done to assess the rate and cause of blindness and low vision, risk factors for various eye diseases, effect of visual impairment on quality of life and barriers to access to eye care services.[11] A South Indian based institute initiated Community Based Rehabilitation (CBR) in a rural district of South India. This institute also analysed barriers for utilisation of rehabilitation programs.[12] Certain community based rehabilitation programs do exist in India which are available via certain NGO's, private institutes and tertiary care centres.

In India, NPCB has been working for a long period to bring down the prevalence of blindness. To achieve this NPCB has adopted intensive IEC (public health prevention program) and has been conducting training sessions for medical officers, eye surgeons, PMOAs and ASHAs for the recognition of all types of ocular ailments. If we look critically at NPCB, cataract related blindness has remained its main target and an equal amount of attention has not been paid for the rehabilitation programs. The ministry of social welfare and empowerment is the nodal ministry for providing physical, vocational and social rehabilitation of incurably blind persons. Many new blind schools have been set up and supported for rehabilitation by this ministry, but the lack of sufficient number of blind schools and trained professionals for vision rehabilitation are the main barrier in our country to educate and rehabilitate the blind persons. There has never been a nationwide epidemiological study on the prevalence and pattern of blindness and in our country only few NGO's and private institutes are actively running rehabilitation training programs. International agencies like Sightsavers International and CBM International already have focus on promoting community based rehabilitation for comprehensive eye care. The physical and social function of the blind person depends a lot on proper utilisation of their remaining visual acuity and only rehabilitation activities can create a more equal society for blinds, promotes opportunities for economic empowerment, livelihood security, achieves their full potentials and enjoy their human rights.

\section{CONCLUSION}

Though government has adopted various programs to reduce the prevalence of blindness, but rehabilitation programs for blind persons are barely available. Keeping the congenital malformations aside, a sizable portion of the incurably blind patients were preventable. Attention should be paid on Community Based Rehabilitation (CBR) along with the existing curative and preventive services to support and rehabilitate the blind people with extra care for children. Regional surveys are not enough for formulation of comprehensive eye care policy in this regard. A nationwide population-based epidemiological study is a must to know the exact number of incurably blind persons, nature of rehabilitation required for them, planning and implementing blindness prevention programs and appropriate allocation of resources.

\section{Practice Points}

- Majority of persons were affected since childhood, leading to long years of compromised quality of life.

- Early screening for eye disease should be made universally available and accessible.

- Provision of diagnostic and treatment facility should be available at feasible and affordable cost to all in need.

- Incurable blind persons should be properly linked to social security measures and more emphasis should be provided towards awareness and demand generation for available governmental/non-governmental schemes.

- Vocational and other rehabilitation measures should be escalated to address the need of those with incurable blindness. 


\section{REFERENCES}

1. Gormezano SR. Promoting independence through low vision rehabilitation. Optometry 2005;76(5):327-31.

2. Thylefors B, Negrel AD, Pararajasegaram R, et al. Global data on blindness. Bull World Health Organ 1995;73(1): 115-21.

3. Mohan M. Survey of blindness, India (1986-89): Summary and results. In: Director general of health services, ministry of health family welfare, and government of India. Present status of national program for control of blindness (NPCB) 1992. New Delhi: Government of India 1992:79-100.

4. Population census of India 2011. http//censusindia.govt.in/

5. Quaterly newsletter (NPCB India). Theme of issue: building up cataract surgical capacity 2012.

6. MoH \& FW (NPCB). Rapid assessment of avoidable blindness. India Report 2006-07.

7. Gieser DK. Visual rehabilitation: the challenge, responsibility, and reward. Ophthalmology 1992;99(10): 1622-5.
8. Fletcher DC. Low vision: the physician's role in rehabilitation and referral. Geriatrics 1994;49(5):50-3.

9. Massof RW, Dagnelie G, Deremeik J, et al. Low vision rehabilitation in the US health care system. J Vis Rehabil 1995;9:3-31.

10. Shamanna BR, Dandona L, Rao GN. Economic burden of blindness in India. Indian J Ophthalmol 1998;46(3): 169-72.

11. Dandona R, Dandona L, Naduvilath TJ, et al. Design of a population based study of visual impairment in India: the Andhra Pradesh eye disease study. Indian J Ophthalmol 1997;45(4):251-7.

12. Vijayakumar V, Datta D, Karthika A, et al. Utilisation of community-based rehabilitation services for incurably blind persons in a rural population of southern India. Indian J Ophthalmol 2003;51(3):273-7. 